\title{
Synthesis of triazolopyridines and triazolopyrimidines using a modified Mitsunobu reaction
}

\author{
Jacques Y. Roberge*, Guixue Yu, Amarendra Mikkilineni, Ximao Wu, Yeheng Zhu, \\ R. Michael Lawrence, and William R. Ewing* \\ Bristol-Myers Squibb Research \& Development, Discovery Chemistry, \\ P.O. Box 5400, Princeton, NJ 08543-5400 \\ E-mail: jacques.roberge@bms.com
}

Dedicated to Professor Madeleine Joullie on the occasion of her $80^{\text {th }}$ birthday

\begin{abstract}
Triazolopyridines and triazolopyrimidines were synthesized using a modified Mitsunobu reaction starting from acylated 2-hydrazinopyridines and acylated-hydrazinopyrimidines under mild conditions.
\end{abstract}

Keywords: Triazolopyridines, triazolopyrimidines, Mitsunobu reaction, intramolecular cyclization

\section{Introduction}

Triazolopyridines and fused triazoles are useful scaffolds for the generation of biologically interesting molecules. ${ }^{1}$ The conventional synthesis of triazolopyridines involves the dehydration of a 2-hydrazidopyridine using refluxing phosphorus oxychloride, concentrated hydrochloric acid or refluxing acetic acid (Scheme 1).,1a These relatively harsh reaction conditions are often incompatible with many acid or base labile functional and protecting groups such as esters or carbamates [t-butyloxycarbonyl (Boc), 9H-fluoren-9-ylmethyloxycarbonyl (Fmoc)], limiting the types of precursors that can be used in forming fused triazoles via these methods. Mild conditions for the formation of triazoles have been described in the literature, ${ }^{3}$ however, significant variations in yields and reaction times limit the choice of substrates that can be utilized. For example, the use of Wamhoff and Zahran's conditions (2 eq. of triphenylphosphine dichloride, 2.8 eq. triethylamine in refluxing acetonitrile) to convert 1a to 2a gave less than 30\% yield. Due to an interest in synthesizing fused [1,2,4]triazolo[4,3-a]pyridine heterocyclic systems for structure-activity relationship (SAR) studies, an effort was initiated to develop a general, mild and efficient method for the synthesis of triazolopyridines and other fused triazoles that would be compatible with amino acid substrates and other polar functional groups. As 
shown conceptually in Scheme 1, it was postulated that a suitably mild dehydrating agent which could activate the carbonyl group of an acylated hydrazinopyridine under conditions that also maintained the nucleophilicity of the pyridine nitrogen could lead to intramolecular cyclization and provide the desired triazolopyridine.

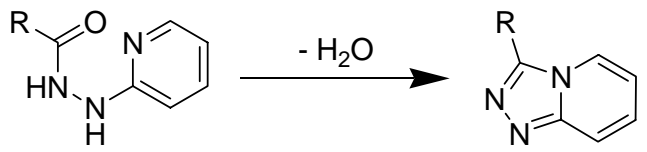

Scheme 1. Dehydrative Cyclization.

\section{Results and Discussion}

The Mitsunobu reaction has been one of the most extensively studied and applied reactions in organic synthesis, particularly in the formation of carbon-heteroatom bonds such as saturated heterocyclic rings, ethers, esters, azides and amines. ${ }^{4}$ The Mitsunobu reaction has also been widely utilized in the formation of tetrazoles. ${ }^{5}$ Activation of amides, including various cyclic amides such as pyridones and pyrimidinones, under Mitsunobu conditions has been well documented. ${ }^{6}$ In addition, the Mitsunobu reaction has been used for the formation of benzoxazoles, ${ }^{7}$ but its general utility in forming heteroaromatic rings, such as triazolopyridines, has not been explored. ${ }^{8}$ Since the formation of triazolopyridines starting from acylated hydrazinopyridines, such as 1a (Scheme 2), requires the loss of one water molecule, any appropriate dehydrating reagent should be able to mediate the cyclization if the reagent is suitably activating and if the pyridine nitrogen has sufficient nucleophilicity. The dehydrating nature of the Mitsunobu reaction suggested it might be effective in mediating the transformation outlined in Scheme 1. As shown in Scheme 2, subjecting acylated hydrazinopyridines $\mathbf{1 a}$ and $\mathbf{1 b}$ to the standard Mitsunobu reaction using triphenylphosphine $\left(\mathrm{Ph}_{3} \mathrm{P}\right)$ and diethyl azodicarboxylate (DEAD) in THF afforded the desired products $\mathbf{2 a}$ (5\%) and $\mathbf{2 b}(20 \%)$.

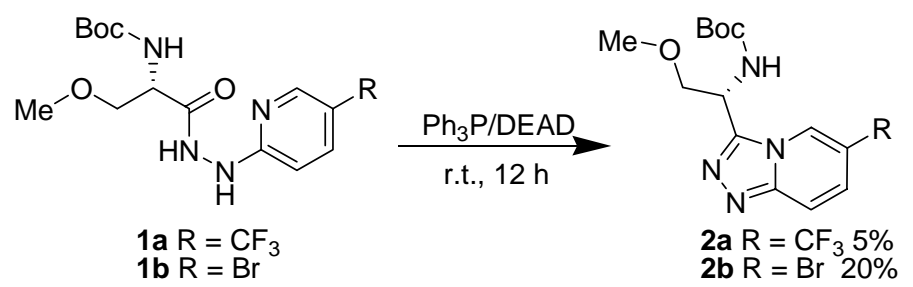

Scheme 2. Triazolopyridines: synthesis from classic Mitsunobu reaction conditions.

Although these initial attempts proceeded in low yields, the formation of the desired triazolopyridines under these mild reaction conditions provided sufficient justification for 
optimizing the reaction. Upon consideration of the proposed mechanism of the Mitsunobu reaction, it seemed reasonable to suggest a reaction mechanism proceeding through intermediate 5 (Scheme 3). ${ }^{9,4 d}$ Addition of transient protecting groups might stabilize the intermediate and allow for the intramolecular attack of the pyridine nitrogen while preventing the decomposition of the starting material.

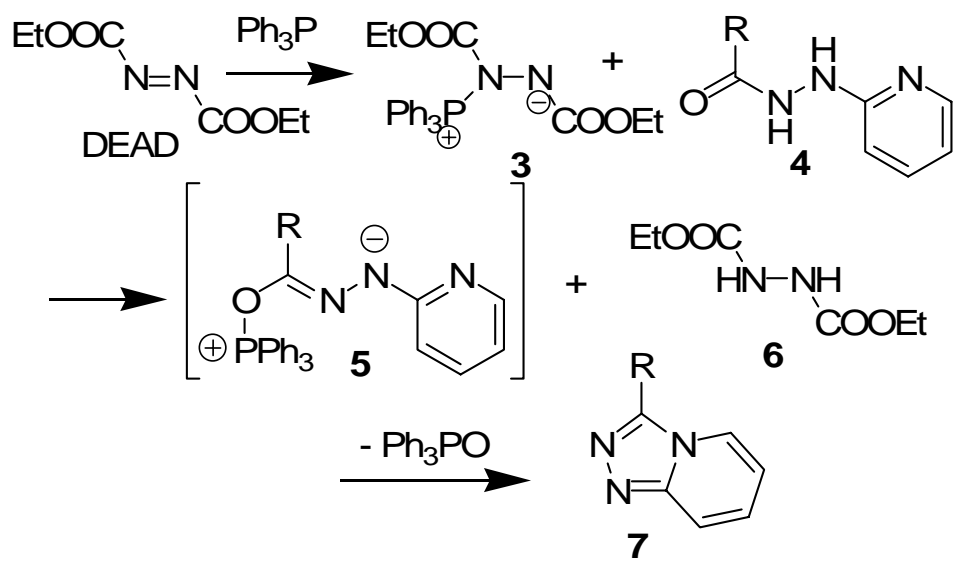

Scheme 3. Putative intermediate 5 from the Misunobu reaction.

To test this hypothesis, the effect on the product yield of incorporating an in situ transient protecting group like trimethylsilyl (TMS) was assessed. Duncia et $a l^{5 \mathrm{~b}}$ reported the use TMS$\mathrm{N}_{3}$ under Mitsunobu conditions to efficiently form tetrazoles. Based on this precedent, TMS- $\mathrm{N}_{3}$ was the first additive that was tried, as shown in Scheme 4 proceeding to the triazolopyridine 7 via the putative intermediate 8 . The addition of $\mathrm{TMS}-\mathrm{N}_{3}$ and triphenylphosphine to the reaction mixture followed by DEAD enhanced the yield of triazolopyridine $2 \mathbf{a}$ from $~ 5 \%$ to $90 \%$, and of triazolopyridine $\mathbf{2 b}$ from $20 \%$ to $95 \%{ }^{10}$ In general, the reactions were complete in less than 10 minutes at room temperature. The formation of tetrazoles using Duncia's conditions is reported to require more than $24 \mathrm{~h}$ and excess azide to complete while in our case the cyclization is rapid and requires only one equivalent of the azide. This favorable outcome is probably due to the intramolecular nature of our reaction.

To understand the reaction further, other silylating agents and azide sources were tried, and it was found that TMS- $\mathrm{N}_{3}$ is the optimal reagent (Table 1). ${ }^{11}$ When no additive was used, less than $21 \%$ of the desired product was observed by LCMS (Entry 1). No starting material remained, as determined by TLC and LCMS, but no other major peaks other than triphenylphosphine oxide and the hydrazine dicarboxylate were observed. Multiple small peaks were observed over the length of the HPLC trace. When TMS-Cl was used, no desired product was observed and the starting material was not consumed (Entry 3). Similar results were also obtained with TMS-I (Entry 4). With TMS-OTf, a modest amount of product was observed (Entry 5, 24\% yield), with the remainder of the mass balance being starting material. With TMS-CN, N,O-bis trimethylsilylacetimidate or $\mathrm{N}, \mathrm{O}$-bis trimethylsilyltrifluoroacetimidate, low levels of product 
were observed with complete consumption of the starting material (Entry 6-8). ${ }^{12}$ The sequence of reagent addition is crucial for the success of the cyclization reaction. DEAD has to be added last, otherwise no difference in product yield was observed relative to those in Scheme 2 (37\% product observed in the LCMS after $72 \mathrm{~h}$ compared to $69 \%$ ). ${ }^{31} \mathrm{P}$ NMR provided evidence that when 1a was mixed with $\mathrm{Ph}_{3} \mathrm{P}$ and TMS- $\mathrm{N}_{3}$ at room temperature, the $\mathrm{Ph}_{3} \mathrm{P}$ only reacted slowly in THF as evidenced by the disappearance of the ${ }^{31} \mathrm{P}$ signal of $\mathrm{Ph}_{3} \mathrm{P}$ at $-4.3 \mathrm{ppm}$ and the appearance of the ${ }^{31} \mathrm{P}$ signal of $\mathrm{Ph}_{3} \mathrm{P}=\mathrm{NTMS}$ at $\delta-0.66 \mathrm{ppm}$ over a period of $6 \mathrm{~h}$. Furthermore, use of commercially available $\mathrm{Ph}_{3} \mathrm{P}=\mathrm{NTMS}$ (Entry 9) instead of $\mathrm{Ph}_{3} \mathrm{P}$ and TMS- $\mathrm{N}_{3}$, failed to effect the cyclization of $\mathbf{1 a}$ and $\mathbf{1 b}$, presumably excluding the formation of $\mathrm{Ph}_{3} \mathrm{P}=\mathrm{NTMS}$ as a possible intermediate.

Addition of excess $\mathrm{Bu}_{4} \mathrm{NN}_{3}$ did not improve the reaction (Entry 10) but when sodium azide or the more THF-soluble cesium azide was added (Entry 11) a significant amount of triazolopyridine was formed. This suggests that the azide plays an important role in this reaction and the impact of the TMS group to the reaction might be only to provide a stable, soluble form of the azide for activation of the active species. ${ }^{11,13}$

Table 1. Additives for the dehydrative cyclization

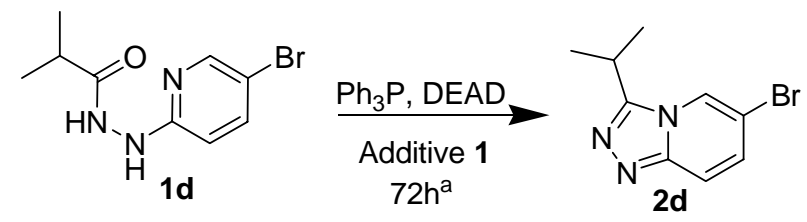

\begin{tabular}{llll}
\hline Entry & Additive 1 & $\% 1 \mathrm{~d}^{\mathrm{b}}$ & $\% 2 \mathrm{~d}$ \\
\hline 1 & None & none & $<21 \%$ \\
2 & TMS- $\mathrm{N}_{3}$ & none & $62 \%(62 \%)^{\mathrm{c}}$ \\
3 & TMS-Cl & $55 \%$ & none \\
4 & TMS-I & $35 \%$ & none \\
5 & TMS-OTf & $10 \%$ & $24 \%$ \\
6 & TMS-CN & none & $<7 \%$ \\
7 & $\mathrm{CH}_{3} \mathrm{C}(\mathrm{OTMS})=$ NTMS & trace & $<22 \%$ \\
8 & $\mathrm{CF}_{3} \mathrm{C}(\mathrm{OTMS})=$ NTMS & none & $<26 \%$ \\
9 & $\mathrm{Ph}_{3} \mathrm{P}=\mathrm{NTMS}$ & none & $<2 \%$ \\
10 & $\mathrm{Bu}_{4} \mathrm{NN}_{3}$ & none & $<1 \%$ \\
11 & $\mathrm{NaN}_{3}$ & none & $39 \%$ \\
12 & $\mathrm{CsN}_{3}$ & none & $45 \%$ \\
\hline
\end{tabular}

${ }^{\mathrm{a}} \mathrm{DEAD}$ (1.5 eq.) was added to a solution of the hydrazide $(50 \mathrm{mg}), \mathrm{Ph}_{3} \mathrm{P}$ (1.2 eq.) and the additive (1 eq.) in THF $(0.2 \mathrm{M})$. All reactions were allowed to proceed for $72 \mathrm{~h}$. The reactions were monitored after 1, 6, 20, and 72h. No changes were observed between 6 and $72 \mathrm{~h}$. ${ }^{\mathrm{b}}$ The percentage of $\mathbf{1 d}$ and $\mathbf{2 d}$ was determined using reverse phase HPLC by integration of the area of 
the signal by ultraviolet detection at $220 \mathrm{~nm}$. The major peak was always $\mathrm{Ph}_{3} \mathrm{PO}$ and was subtracted from the total integration before calculating the percentage of product. ${ }^{\mathrm{C}}$ Isolated yield.

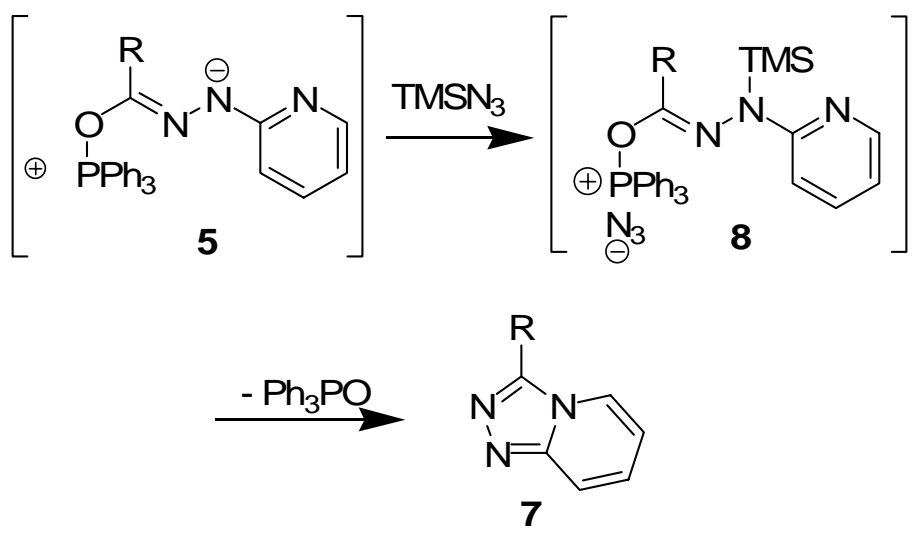

Scheme 4. TMS azide; possible role.

When diisopropylazodicarboxylate (DIAD) was used as an alternative to DEAD, it was found that in the absence of the acylated 2-hydrazinopyridines, a white precipitate formed upon addition of 1 eq. of DIAD to an equimolar mixture of $\mathrm{Ph}_{3} \mathrm{P}$ and $\mathrm{TMS}-\mathrm{N}_{3}$ at $0.1 \mathrm{M}$, or in more concentrated solutions. No precipitate was formed with any of the other pairs of reagents at 0.1 M. This white solid also formed in ether, and was soluble in DCM or chloroform. The solid was found to be moisture sensitive and thermally unstable. NMR studies showed the presence of the phosphine, DIAD but no TMS group. When cesium azide was used instead of $\mathrm{TMSN}_{3}$, a white precipitate also formed. The IR of the solid showed the presence of a band at $2100 \mathrm{~cm}^{-1}$. This solid was able to perform the triazolopyridine cyclization but excess reagent was required to complete the reaction, indicating that this species might be involved in the cyclization reaction but another component is needed to make the conversion efficient, possibly the TMS group. Attempts to obtain crystals for an X-ray structure determination have been unsuccessful to date. ${ }^{14}$ Other possible mechanisms are shown in Scheme 5. Pathway A shows the formation of a DEAD, triphenylphosphine and azide complex $\mathbf{9}$ in which the TMS group (or a metal) is associated with the negative charge on the DEAD. Displacement of the azide by nucleophilic attack of the carbonyl of the acyl hydrazine $\mathbf{4}$ results in a complex $\mathbf{1 0}$ that proceeds onto product 7. Alternatively, as shown in Pathway B, attack of the acyl hydrazine $\mathbf{4}$ can displace the DEAD from the complex 9. By this pathway, the triazolopyridine $\mathbf{7}$ is then formed through loss of triphenylphosphine oxide and azide. 


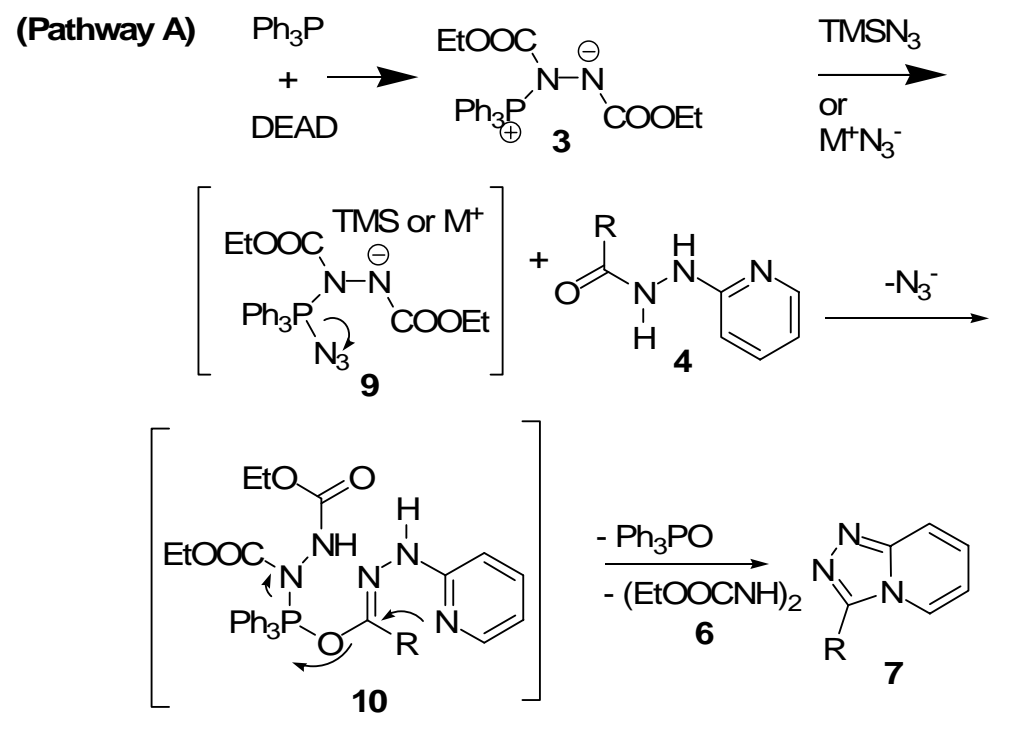

(Pathway B)
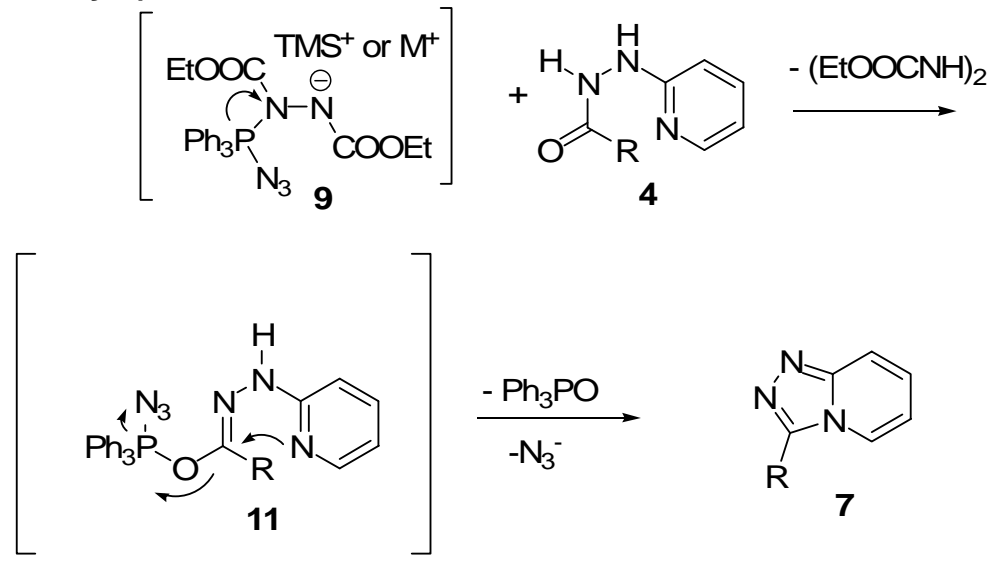

Scheme 5. Other possible reaction mechanisms.

The potential scope and application of the TMS- $\mathrm{N}_{3}$ assisted Mitsunobu reaction to form triazolopyridines is shown in Table 2. Amino acid protecting groups such as Boc and Fmoc are compatible with the reaction conditions. Similarly, methyl ethers and benzyl, t-butyl, methyl and ethyl esters can also be used. Furthermore, Table 2 includes several examples of triazolopyridines derived from amino acids. These products have potential use as peptide mimetics as the triazolo ring can be envisioned to be an amide isostere. Triazolopyridines formed from amino acid precursors show a high retention of stereochemistry (ee = 99\%) (examples 2a, $\mathbf{2 k}$, 2l, Table 2, as determined by using chiral HPLC or SFC, see experimental section for details). Acyl hydrazinopyridines in which $\mathrm{R}^{1}$ is a secondary carbon were also found to undergo the modified Mitsunobu reaction (2d, 2g, 2h, 2i, 2j, Table 2). Table 3 shows that triazolopyrimidines (2r-2u) can be synthesized using this method, although higher reaction temperatures $\left(50^{\circ} \mathrm{C}\right)$ and longer times are needed. 
Table 2. Synthesis of triazolopyridines ${ }^{15}$

2)


Table 3. Syntheses of triazolopyrimidines ${ }^{16}$

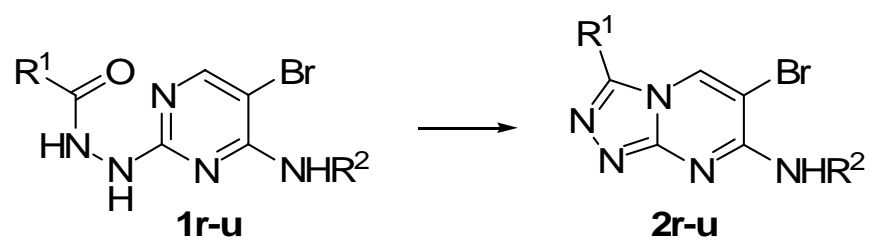

\begin{tabular}{clcc}
\hline Entry & $\mathrm{R}^{1}$ & $\mathrm{R}^{2}$ & Yield (\%) \\
\hline $\mathbf{2 r}$ & $-\mathrm{CH}_{2} \mathrm{OBn}$ & $\mathrm{Am}^{\mathrm{a}}$ & 31 \\
$\mathbf{2 s}$ & $-\mathrm{COOMe}$ & $\mathrm{Am}$ & 53 \\
$\mathbf{2 t}$ & $-\mathrm{CH}_{2} \mathrm{COOEt}$ & $\mathrm{Am}$ & 60 \\
$\mathbf{2 u}$ & $-\mathrm{COOMe}$ & $\mathrm{Bn}$ & 22 \\
\hline
\end{tabular}

${ }^{\mathrm{a}} \mathrm{Am}$ : amyl $\left(n \mathrm{C}_{5} \mathrm{H}_{11}\right)$

\section{Conclusions}

In summary, a general application of the Mitsunobu reaction for the synthesis of triazolopyridines and triazolopyrimidines (Tables 2 and 3) has been developed using $\mathrm{TMS}^{-\mathrm{N}_{3}}$ as an additive. The described methodology has general application for the formation of derivatized triazolopyridines under mild conditions, and for the generation of peptidomimetics when amino acids are used as precursors.

\section{Acknowledgements}

We thank Prof. Philip Baran for helpful discussions.

\section{Experimental Section}

General Procedures. Proton and carbon NMR spectra were recorded on one of the following instruments: Bruker DRX-400 MHz , Jeol ECL-400 or $500 \mathrm{MHz}$ instrument. Analytical high pressure liquid chromatography (HPLC) and liquid chromatography/mass spectrometry (LC/MS) analyses were conducted using Shimadzu LC-10AS pumps and a SPD-10AV UV-vis detector. MS detection was performed with a Micromass Platform LC spectrometer. HPLC and LC/MS methods are detailed below. Preparative Reverse Phase (RP) HPLC was performed using two Shimadzu LC-8A pumps and a SPD-10AV UV-vis detector set at $220 \mathrm{~nm}$ on C18 RP columns (YMC Pack ODSA S5 $20 \times 100 \mathrm{~mm}$ or $30 \times 250 \mathrm{~mm}$ ) using methanol/water mixtures buffered 
with $0.1 \%$ trifluoroacetic acid. Enantiomeric excess was determined using supercritical fluid chromatography (SFC, Berger) using a ChiralPak AD column (4.6 x $250 \mathrm{~mm}, 10 \mu \mathrm{m}$ particles) at $2 \mathrm{~mL} / \mathrm{min}$ flow rate of a $17 \% \mathrm{MeOH}$ in $\mathrm{CO}_{2}$ with UV detection at $260 \mathrm{~nm}$ or by HPLC with a Daicel Chiralcel AD column (4.6 x $250 \mathrm{~mm})$ using an isocratic mixture of 6\% isopropanol in hexanes at a flow of $1 \mathrm{~mL} / \mathrm{min}$ with UV detection at $220 \mathrm{~nm}$. High-resolution mass spectra (HMRS) were recorded on a JEOL SX102 mass spectrometer. Elemental analyses were performed by Robertson Microlit Laboratories and the results obtained were within $\pm 0.4 \%$ of the theoretical values, unless otherwise indicated. All non-aqueous reactions were carried out under an atmosphere of nitrogen or argon at ambient temperature unless otherwise noted. Commercial reagents and solvents were used without further purification.

2-Hydrazopyridines (5- $\mathrm{Br}$ and $5-\mathrm{CF}_{3}$ ) were commercially availlable. Acylations of the hydrazopyridines were done using the mixed anhydride carbonate method or by using polymer supported IIDQ $^{17}$.

\section{General procedure 1}

Preparation of 1a. Polymer-supported IIDQ. 2-Hydrazinyl-5-(trifluoromethyl) pyridine (165 $\mathrm{mg}, 0.93 \mathrm{mmol}$ ) and (S)-2-(tert-butoxycarbonylamino)-3-methoxypropanoic acid (204 mg, 0.93 mmol) were added to PS-IIDQ (Novabiochem $1.8 \mathrm{mmol} / \mathrm{g}, 776 \mathrm{mg}, 1.4 \mathrm{mmol}$ ) pre-swollen in acetonitrile $(6 \mathrm{~mL})$ and the reaction mixture was shaken at room temperature. The resin was filtered and washed with 3 cycles of DCM and $\mathrm{MeOH}$. The filtrates were combined and concentrated in vacuo to give $425 \mathrm{mg}$ of yellow oil. The oil was purified by flash (ISCO $12 \mathrm{~g}$, hexane to ethyl acetate) to give a yellow solid (336.7 mg, $0.85 \mathrm{mmol}, 91 \%$ yield); $\mathrm{MH}+379.2$; ${ }^{1} \mathrm{H}$ NMR (500 MHz, CDCl3) $\delta$ ppm 9.39 (br. s., 1H), 8.40 (br. s., 1H), 8.32 (s, 1H), 7.66 (dd, J= 8.8, 2.2 Hz, 1H), 6.78 (d, J= 8.8 Hz, 1H), 6.47 (d, J= 7.7 Hz, 1H), 4.27 (dd, J= 13.2, $6.6 \mathrm{~Hz}, 1 \mathrm{H}$ ), 3.61 (dd, J= 8.8, 4.9 Hz, 1H), 3.54 (dd, J= 9.1, 6.3 Hz, 1H), 3.35 (s, 3H), 1.44 (s, 9H).

\section{General procedure 2}

Preparation of 1d. Mixed anhydride. Isobutyl chloroformate $(0.84 \mathrm{~mL}, 6.4 \mathrm{mmol})$ was added dropwise to a solution of isobutyric acid $(0.59 \mathrm{~mL}, 6.4 \mathrm{mmol})$ and $N$-methylmorpholine $(0.70$ $\mathrm{mL}, 6.4 \mathrm{mmol})$ in THF $(11 \mathrm{~mL})$. A white precipitate formed and the mixture was stirred for 5 min. 5-Bromo-2-hydrazinopyridine ( $1.0 \mathrm{~g}, 5.3 \mathrm{mmol}$ ) was added and the mixture was stirred for 1h. The reaction was diluted with $200 \mathrm{~mL}$ water and was stirred overnight. The reaction was made basic with saturated sodium bicarbonate and the solid was filtered, washed with water and dried under reduced pressure overnight to give a white solid (1.17 g, 3.99 mmol, 75 \% yield). LCMS (Phenominex, Luna C18, 4.6 X $50 \mathrm{~mm}, 4$ min gradient from 10\% $\mathrm{MeOH}$, 90\% water, $0.1 \%$ TFA to $90 \% \mathrm{MeOH}, 10 \%$ water, $0.1 \%$ TFA) $1.54 \mathrm{~min},>88 \%$, $\mathrm{MH}+260.2 ; 2.40 \mathrm{~min} 13 \%$, $\mathrm{MH}+288.2$ isobutylcarbamate analog. TLC (70\% EA/hex). The product was recrystalized from DCM. ${ }^{1} \mathrm{H}$ NMR (500 MHz, DMSO-D6) $\delta$ ppm 9.72 (s, 1H), 8.48 (s, 1H) , 8.11 (d, J= 2.2 Hz, 1H) , 7.67 (dd, J= 8.8, 2.2 Hz, 1H) , 6.49 (d, J=8.8 Hz, 1H), 2.43-2.49 (m, 1H), 1.05 (d, J= 7.1 $\mathrm{Hz}, 6 \mathrm{H})$. 


\section{Preparation of $1 \mathrm{u}$ is representative for the preparation of the pyrimidines}

(a) Benzylamine addition. A solution of benzylamine (3.02 $\mathrm{mL}, 27.6 \mathrm{mmol})$ and triethylamine $(4.40 \mathrm{~mL}, 31.6 \mathrm{mmol})$ in ethanol $(4 \mathrm{~mL})$ was added drop-wise to a solution of 5-bromo-2,4dichloropyrimidine (6.00 g, $26.3 \mathrm{mmol})$ in ethanol $(13 \mathrm{~mL})$ and the mixture was stirred for $1 \mathrm{~h}$. A white precipitate formed. The reaction mixture was poured into water $(100 \mathrm{~mL})$ and the white solid was filtered washed with water and dried under reduced pressure to give $7.86 \mathrm{~g}$ (97\% yield) of white solid: LCMS Pos/neg 3.30 min, 94\% pure, MH+ 298.88, M-H 295.85 Phenominex ODS 4.6 X 50 mm, 4 mL min, 4 min gradient 100\% A to 100\% B (A: 10\% methanol, 90\% water, 10 mM NH${ }_{4} \mathrm{OAc}$; B: 10\% water, 90\% methanol, $10 \mathrm{mM} \mathrm{NH} 4 \mathrm{OAc}$, UV $220 \mathrm{~nm}$ ), ${ }^{1} \mathrm{H}$ NMR (400 MHz, DMSO-D6) $\delta$ ppm 8.33 (t, J=6.2, 1H), 8.27 (s, 1H), 7.2-7.35 (m, 5H), 4.56 (d, J= 6.2 Hz). ${ }^{13} \mathrm{C}$ NMR (100 MHz, DMSO-D6) $\delta$ ppm 159.37, 158.08, 156.84, 138.47, 128.27 (2C), 127.19 (2C), 126.90, 102.51, 43.88.

(b) Hydrazine addition. Hydrazine monohydrate $(2.44 \mathrm{~mL}, 50.2 \mathrm{mmol})$ was added to a solution of $\mathrm{N}$-benzyl-5-bromo-2-chloropyrimidin-4-amine (5.0 g, $16.7 \mathrm{mmol}$ ) and triethylamine (3.50 $\mathrm{mL}, 25.1 \mathrm{mmol})$ in ethanol $(33 \mathrm{~mL})$ and the mixture was refluxed for $3.5 \mathrm{~h}$. The clear colorless solution was cooled to room temperature and was poured into iced water (200 mL). The white precipitate was filtered, washed with water to give $4.79 \mathrm{~g}$ ( $97 \%$ yield) of a pinkish solid after drying overnight under reduced pressure. LCMS Pos/neg $2.70 \mathrm{~min}$, 90\% pure (the rest was the starting chloride), $\mathrm{MH}+$ 293.93, Phenominex ODS 4.6 X $50 \mathrm{~mm}, 4 \mathrm{~mL} \mathrm{~min}, 4 \mathrm{~min}$ gradient $100 \%$ A to $100 \%$ B (A: 10\% methanol, $90 \%$ water, $10 \mathrm{mM} \mathrm{NH}_{4} \mathrm{OAc}$; B: $10 \%$ water, $90 \%$ methanol, $10 \mathrm{mM} \mathrm{NH}$ OAc, UV $220 \mathrm{~nm}$ ); ${ }^{1} \mathrm{H}$ NMR (500 MHz, DMSO-D6) $\delta$ ppm 7.81 (s, 1H), 7.70 (s, 1H), 7.1-7.35 (m, 6H), 4.49 (d, J=6.0 Hz, 2H), 3.97 (br. s, 2H); ${ }^{13} \mathrm{C}$ NMR (125 MHz, DMSO-D6) $\delta$ ppm 162.92, 157.76, 157.79, 139.99, 128.30 (2C), 127.50 (2C) 127.20, 126.56, 43.36.

(c) Acylation. Methyl 2-chloro-2-oxoacetate $(0.62 \mathrm{~mL}, 6.7 \mathrm{mmol})$ was slowly added to a cold ($20{ }^{\circ} \mathrm{C}$ ) solution of $\mathrm{N}$-benzyl-5-bromo-2-hydrazinylpyrimidin-4-amine (1.79 g, $\left.6.1 \mathrm{mmol}\right)$ and triethylamine $(1.66 \mathrm{~mL}, 12.2 \mathrm{mmol})$ in THF $(20 \mathrm{~mL})$ and the mixture was slowly warmed to room temperature over $3 \mathrm{~h}$. The mixture was poured into $50 \mathrm{~mL}$ of ice cold water and was stirred for $15 \mathrm{~min}$. The solid was filtered to give $572.4 \mathrm{mg}$ of yellow solid The filtrate was extracted with ethyl acetate (3 X $50 \mathrm{~mL}$ ) washed with brine $(30 \mathrm{~mL})$ dried with sodium sulfate and concentrated to give $\sim 900 \mathrm{mg}$ of yellow foam. The foam dissolved in hot ethyl acetate (20$30 \mathrm{~mL})$ and the product was precipitated by adding heptane $(5-10 \mathrm{~mL})$ to give $500 \mathrm{mg}$ of white solid (98\% pure by LCMS Pos/neg.2.48 min, MH+2 379.89, M-H 377.85). ${ }^{1} \mathrm{H}$ NMR (500 MHz, DMSO-D6) $\delta$ ppm 10.65 (s, 1H), 8.80 (s, 1H), 7.94 (s, 1H), 7.57 (t, J= 6.0, 1H), 7.15-7.3 (m, 6H), 4.50 (br.s, 2H), 3.79 (s, 3H); ${ }^{13} \mathrm{C}$ NMR (125 MHz, DMSO-D6) $\delta$ ppm 160.68, 158.03, 155.92, 139.63, 128.07, 127.55, 126.63, 52.84, 43.35.

\section{(R)-tert-butyl \\ 2-methoxy-1-(6-(trifluoromethyl)-[1,2,4]triazolo[4,3-a]pyridin-3-} yl)ethylcarbamate (2a). White solid, yield: 90\%; ${ }^{1} \mathrm{H}$ NMR (500 MHz, $\left.\mathrm{CDC}_{13}\right) \delta 8.80(\mathrm{~s}, 1 \mathrm{H})$, 7.86 (d, J= $10 \mathrm{~Hz}, 1 \mathrm{H}), 7.39$ (d, J= $10 \mathrm{~Hz}, 1 \mathrm{H}), 5.58$ (d, J= $10 \mathrm{~Hz}, 1 \mathrm{H})$, 5.6-5.4 (m, 1H), 4.04$4.12(\mathrm{~m}, 1 \mathrm{H})$ 3.82-3.88 (m, 1H), $3.41(\mathrm{~s}, 3 \mathrm{H}), 1.45(\mathrm{~s}, 9 \mathrm{H}) \cdot{ }^{13} \mathrm{C}$ NMR $\left(125 \mathrm{MHz}, \mathrm{CDCl}_{3}\right) \delta$ 
155.58, 149.80, 147.45, 132.11, 131.88, 123.54, 118.32, 117.29, 80.91, 73.14, 59.20, 46.02, 28.15. Exact mass calcd. $(\mathrm{M}+\mathrm{H})$ for $\mathrm{C}_{15} \mathrm{H}_{19} \mathrm{~F}_{3} \mathrm{~N}_{4} \mathrm{O}_{3}$ : 361.1488; found: 361.1487. Elemental Analysis for $\mathrm{C}_{15} \mathrm{H}_{19} \mathrm{~F}_{3} \mathrm{~N}_{4} \mathrm{O}_{3}$ : calcd. C, 50.00\%; H, 5.31\%; F, 15.82\%; N, 15.55\%; O, 13.32\%; found: C, 50.07\%; H, 5.13\%; F, 15.64\%; N, 15.45\%. Enantiomeric excess: 99\% (supercritical fluid chromatography (SFC, Berger) using a ChiralPak AD column (4.6 x 250 mm, $10 \mu \mathrm{m}$ particles) at $2 \mathrm{~mL} / \mathrm{min}$ flow rate of a $17 \% \mathrm{MeOH}$ in $\mathrm{CO}_{2}$ with $\mathrm{UV}$ detection at $260 \mathrm{~nm}$ )

(R)-tert-butyl 2-methoxy-1-(6-bromo-[1,2,4]triazolo[4,3-a]pyridin-3-yl)ethylcarbamate (2b). White solid, yield: 95\%; ${ }^{1} \mathrm{H}$ NMR $\left(500 \mathrm{MHz}, \mathrm{CDCl}_{3}\right) \delta 8.67(\mathrm{~s}, 1 \mathrm{H}), 7.98$ (d, J= $\left.10 \mathrm{~Hz}, 1 \mathrm{H}\right)$, 7.56 (d, J= $10 \mathrm{~Hz}, 1 \mathrm{H}), 5.89$ (d, J= $10 \mathrm{~Hz}, 1 \mathrm{H}), 5.6-5.4$ (m, 1H), 4.08-4.00 (m, 1H) 3.94-3.88 (m, $1 \mathrm{H}), 3.40$ (s, 3H), 1.45 (s, 9H). ${ }^{13} \mathrm{C}$ NMR (125 MHz, $\left.\mathrm{CDCl}_{3}\right) \delta$ 155.56, 147.02, 146.10, 134.09, 124.12, 115.63, 110.45, 81.06, 72.61, 59.18, 45.97, 28.10. Exact mass calcd. (M+H) for $\mathrm{C}_{14} \mathrm{H}_{19} \mathrm{BrN}_{4} \mathrm{O}_{3}$ : 371.0719; found: 371.0736.

6-Bromo-3-isopropyl-[1,2,4]triazolo[4,3-a]pyridine (2d). White solid, yield 62\%; ${ }^{1} \mathrm{H}$ NMR (500 MHz, CDCl3) $\delta$ ppm 8.09 (br. s., $1 \mathrm{H}$ ), 7.66 (d, J=8.8 Hz, $1 \mathrm{H}$ ), 7.27 (dd, J=9.9, $1.6 \mathrm{~Hz}, 1$ H), 3.36 (dq, $1 \mathrm{H}), 1.54$ (d, J=7.1 Hz, $6 \mathrm{H})$; Litt.: ${ }^{17}{ }^{1} \mathrm{H}$ NMR (400 MHz, CDCl3): $\delta 8.06$ (s, 1 H), 7.64 (d, J= 9.5 Hz, 1 H), 7.24 (d, J= 9.5 Hz, 1 H), 3.33 (m, J= 7.0 Hz, $1 \mathrm{H}$ ), 1.52 (d, J= 7.0 $\mathrm{Hz}, 6 \mathrm{H}) .{ }^{13} \mathrm{C} \mathrm{NMR}\left(126 \mathrm{MHz}, \mathrm{CDCl}_{3}\right) \delta \mathrm{ppm} 151.13,148.40,130.06,121.93,117.34,108.48$, 25.13, 20.12. (Exact mass calcd. $(\mathrm{M}+\mathrm{H})$ for $\mathrm{C}_{9} \mathrm{H}_{10} \mathrm{BrN}_{3}$ : 240.0136; found: 240.0146.

3-(Pyridin-3-yl)-6-(trifluoromethyl)-[1,2,4]triazolo[4,3-a]pyridine (2e). White solid, yield 53\%; ${ }^{1} \mathrm{H}$ NMR (500 MHz, $\mathrm{CDCl}_{3}$ ) $\delta 10.33$ (s, 1H), 8.75 (d, J= $5 \mathrm{~Hz}, 1 \mathrm{H}$ ), 8.52 (d, J= $10 \mathrm{~Hz}$, $1 \mathrm{H}), 8.07$ (d, J= 10Hz, 1H), 7.91-7.95 (m, 1H), 7.56 (d, J= $10 \mathrm{~Hz}, 1 \mathrm{H}), 7.43-7.46(\mathrm{~m}, 1 \mathrm{H}) .{ }^{13} \mathrm{C}$ NMR (125 MHz, $\left.\mathrm{CDCl}_{3}\right) \delta$ 149.98, 148.86, 147.12, 144.92, 137.34, 126.94, 126.89, 124.48, 122.83, 119.51, 119.24, 118.97, 118.68, 116.76. Exact mass calcd. $(\mathrm{M}+\mathrm{H})$ for $\mathrm{C}_{12} \mathrm{H}_{7} \mathrm{~F}_{3} \mathrm{~N}_{4}$ : 265.0701; found: 265.0699.

3-(Pyridin-3-yl)-6-bromo -[1,2,4]triazolo[4,3-a]pyridine (2f). White solid, yield 62\%; ${ }^{1} \mathrm{H}$ NMR (500 MHz, CDCl $) \delta 10.12(\mathrm{~s}, 1 \mathrm{H}), 8.77$ (d, J= $5 \mathrm{~Hz}, 1 \mathrm{H}), 8.52$ (d, J= $10 \mathrm{~Hz}, 1 \mathrm{H}), 7.90-$ $7.94(\mathrm{~m}, 2 \mathrm{H}), 7.50$ (d, J= $10 \mathrm{~Hz}, 1 \mathrm{H}), 7.40-7.44$ (m, 1H). ${ }^{13} \mathrm{C}$ NMR (125 MHz, CDCl3) $\delta$ 149.04, 148.86, 147.45, 143.87, 137.33, 132.53, 127.20, 124.31, 122.86, 116.22, 110.08. Exact mass calcd. $(\mathrm{M}+\mathrm{H})$ for $\mathrm{C}_{11} \mathrm{H}_{7} \mathrm{BrN}_{4}$ : 274.9932; found: 274.9930 .

tert-Butyl 4-(6-(trifluoromethyl)-[1,2,4]triazolo[4,3-a]pyridin-3-yl)piperidine-1-carboxylate (2g). White solid, yield 69\%; ${ }^{1} \mathrm{H}$ NMR (500 MHz, CDCl $) \delta 8.25$ (s, 1H), 7.83 (d, 1H, J= 9.90 Hz), 7.35-7.25 (dm, 1H, J= 9.90 Hz), 4.19 (br., 2H), 3.24-3.18 (m, 1H), 2.98 (br., 2H), 1.99 (br., 4H), 1.42 (s, 9H). ${ }^{13} \mathrm{C} \mathrm{NMR}\left(125 \mathrm{MHz}, \mathrm{CDCl}_{3}\right)$ 154.59, 150.18, 149.22, 131.89, 122.82 (q, J= $272 \mathrm{~Hz}$ ), 122.76, 118.47(q, J= $36 \mathrm{~Hz}), 118.05$, 79.89, 32.55, 29.38, 28.39. Exact mass calcd. $(\mathrm{M}+\mathrm{H})$ for $\mathrm{C}_{17} \mathrm{H}_{22} \mathrm{~N}_{4} \mathrm{O}_{2} \mathrm{~F}_{3}$ : 371.1695; found: 371.1685 .

tert-Butyl 4-(6-bromo-[1,2,4]triazolo[4,3-a]pyridin-3-yl)piperidine-1-carboxylate (2h). White solid, yield 50\%; ${ }^{1} \mathrm{H}$ NMR (500 MHz, $\left.\mathrm{CDCl}_{3}\right) \delta 8.04(\mathrm{~s}, 1 \mathrm{H}), 7.63(\mathrm{~d}, 1 \mathrm{H}, \mathrm{J}=9.9 \mathrm{~Hz})$, 7.24 (d, 1H, J= 9.4 Hz), 4.17 (br., 2H), 3.14 (br., 1H), 2.95 (br., 2H), 1.18 (br., 4H), 1.21 (s, 9H). ${ }^{13} \mathrm{C} \mathrm{NMR}\left(125 \mathrm{MHz}, \mathrm{CDCl}_{3}\right.$ ) 154.62, 148.80, 148.37, 130.56, 121.75, 117.46, 109.00, 77.26, 32.68, 29.27, 28.41. Exact mass calcd. $(\mathrm{M}+\mathrm{H})$ for $\mathrm{C}_{16} \mathrm{H}_{22} \mathrm{BrN}_{4} \mathrm{O}_{2}$ : 381.0926; found: 381.0890 . 
(S)-tert-Butyl 2-(6-(trifluoromethyl)-[1,2,4]triazolo[4,3-a]pyridin-3-yl)pyrrolidine-1-carboxylate (2i). White solid, yield 55\%; ${ }^{1} \mathrm{H}$ NMR (500 MHz, $\left.\mathrm{CDCl}_{3}\right) \delta 9.35$ (s, 1H), 7.94 (d, 1H, J= 8.8 Hz), 7.45 (d, 1H, J= 8.8 Hz), 5.41 (m, 1H), 3.53 (m, 1H), 3.41 (m, 1H), 2.72 (br., 1H), 2.45 (br., 1H), 2.25 (br., 1H), 2.10 (br., 1H), 1.37 (s, 9H). ${ }^{13} \mathrm{C}$ NMR (125 MHz, $\mathrm{CDCl}_{3}$ ) 155.50, 149.67, 149.07, 131.87, 123.05 (q, J= 272 Hz), 117.86 (q, J= 36 Hz), 116.96, 77.26, 51.54, 46.66, 31.53, 28.20, 22.59. Exact mass calcd. $(\mathrm{M}+\mathrm{H})$ for $\mathrm{C}_{16} \mathrm{H}_{19} \mathrm{~N}_{4} \mathrm{O}_{2}$ : 357.1538; found: 357.1554.

(S)-tert-Butyl 2-(6-bromo-[1,2,4]triazolo[4,3-a]pyridin-3-yl)pyrrolidine-1-carboxylate (2j). White solid, yield 40\%; ${ }^{1} \mathrm{H}$ NMR $\left(500 \mathrm{MHz} \mathrm{CDCl}_{3}\right) \delta 8.83(\mathrm{~s}, 1 \mathrm{H}), 7.60$ (d, 1H, J= 8.8 Hz), 7.24 (d, 1H, J= 9.4 Hz), 5.30 (br., 1H), 3.48 (m, 1H), 3.42 (br., 1H), 2.60 (br., 1H), 2.45 (br., 1H), 2.25 (br., 1H), 2.03 (br., 1H), 1.38(s, 9H). ${ }^{13} \mathrm{C}$ NMR (125 MHz, $\mathrm{CDCl}_{3}$ ) 147.50, 131.50, 124.50, 116.00, 108.75, 77.25, 52.00, 46.64, 30.54, 28.33, 24.77. Exact mass calcd. (M+H) for $\mathrm{C}_{15} \mathrm{H}_{20} \mathrm{BrN}_{4} \mathrm{O}_{2}$ : 368.0770; found: 368.0739.

(S)-tert-Butyl 2-(tert-butoxycarbonylamino)-3-(6-(trifluoromethyl)-[1,2,4]triazolo[4,3-a]pyridin-3yl)propanoate (2k). White solid, yield 71\%; ${ }^{1} \mathrm{H}$ NMR (500 MHz, $\left.\mathrm{CDCl}_{3}\right) \delta 8.53(\mathrm{~s}, 1 \mathrm{H}), 7.82$ (d, 1H, J= 9.9 Hz), 7.35 (d, 1H, J=9.4 Hz), 5.67-5.62 (m, 1H), 4.65-4.60 (m, 1H), 3.74-3.60 (m, 2H), 1.37 (s, 18H). ${ }^{13} \mathrm{C}$ NMR (125 MHz, $\left.\mathrm{CDCl}_{3}\right) \delta 169.28,155.46,149.38,145.01,122.87$, 122.78, 122.23, 118.48, 117.59, 83.32, 77.25, 52.34, 28.17, 27.78. Exact mass calcd. (M+H) for $\mathrm{C}_{19} \mathrm{H}_{26} \mathrm{~N}_{4} \mathrm{O}_{4} \mathrm{~F}_{3}$ : 431.1906; found: 431.1888. Enantiomeric excess: 99\% as determined with HPLC with a Daicel Chiralcel AD column (4.6 x $250 \mathrm{~mm})$ using an isocratic mixture of 6\% isopropanol in hexanes at a flow of $1 \mathrm{~mL} / \mathrm{min}$ with UV detection at $220 \mathrm{~nm}$.

(R)-tert-Butyl 2-(tert-butoxycarbonylamino)-3-(6-(trifluoromethyl)-[1,2,4]triazolo[4,3-a]pyridin3-yl)propanoate (2l). White solid, yield 55\%; ${ }^{1} \mathrm{H}$ NMR (500 MHz, $\left.\mathrm{CDCl}_{3}\right) \delta 8.53$ (s, 1H), 7.83 (d, 1H, J= 9.9 Hz), 7.36 (d, 1H, J= 9.4 Hz), 5.67-5.62 (m, 1H), 4.65-4.60(m, 1H), 3.74-3.60 (m, 2H), 1.37 (s, 18H). ${ }^{13} \mathrm{C}$ NMR (125 MHz, $\left.\mathrm{CDCl}_{3}\right) \delta 169.29,155.46,149.39,145.01,122.87$, 122.77, 122.25, 118.48, 117.59, 83.33, 80.37, 76.75, 52.35, 28.18, 27.80. Exact mass calcd. $(\mathrm{M}+\mathrm{H})$ for $\mathrm{C}_{19} \mathrm{H}_{26} \mathrm{~N}_{4} \mathrm{O}_{4} \mathrm{~F}_{3}$ : 431.1906; found: 431.1909. Enantiomeric excess: 99\% as determined with HPLC with a Daicel Chiralcel AD column (4.6 x $250 \mathrm{~mm})$ using an isocratic mixture of 6\% isopropanol in hexanes at a flow of $1 \mathrm{~mL} / \mathrm{min}$ with UV detection at $220 \mathrm{~nm}$.

(S)-Benzyl 4-(tert-butoxycarbonylamino)-4-(6-(trifluoromethyl)-[1,2,4]triazolo[4,3-a]pyridin-3yl)butanoate (2m). White solid, 39\% yield; ${ }^{1} \mathrm{H}$ NMR (500 MHz, $\left.\mathrm{CDCl}_{3}\right) \delta 8.86(\mathrm{~s}, 1 \mathrm{H}), 7.81(\mathrm{~d}$, $1 \mathrm{H}, \mathrm{J}=10 \mathrm{~Hz}$ ), 7.42-7.3 (m, 6H), 5.5-5.4 (br, 1H), 5.32-5.25 (m, 1H), 5.12 (s, 2H), 2.8-2.58 (m, 3H), 2.53-2.4 (m, 1H), 1.42(s, 9H). $\left.{ }^{13} \mathrm{C} \mathrm{NMR} \mathrm{(125} \mathrm{MHz,} \mathrm{CDCl}_{3}\right) \delta 172.54,155.78,149.73$, 148.32, 135.61, 128.51, 128.24, 123.34, 122.82(q, J= $272 \mathrm{~Hz}), 118.47$ (q, J= $36 \mathrm{~Hz}), 117.24$, 80.87, 66.58, 44.74, 30.23, 28.08, 27.92. Exact mass calcd. $(\mathrm{M}+\mathrm{H})$ for $\mathrm{C}_{23} \mathrm{H}_{25} \mathrm{~F}_{3} \mathrm{~N}_{5} \mathrm{O}_{4}$ : 479.1918; found: 479.1906.

(S)-Benzyl 4-(tert-butoxycarbonylamino)-4-(6-bromo-[1,2,4]triazolo[4,3-a]pyridin-3-yl)butanoate (2n). White solid, 33\% yield; ${ }^{1} \mathrm{H}$ NMR $\left(500 \mathrm{MHz} \mathrm{CDCl}_{3}\right) \delta 8.40$ (s, 1H), 7.52 (d, 2H, J= 8.6 $\mathrm{Hz}$ ), 7.27-7.19 (m, 6H), 5.29-5.2 (m, 1H), 5.2-5.1 (m, 1H), 5.02 (s, 2H), 2.58-2.52 (m, 1H), 2.52.48 (m, 2H), 2.33-2.28 (m, 1H), $1.30(\mathrm{~s}, 9 \mathrm{H}) .{ }^{13} \mathrm{C} \mathrm{NMR}\left(125 \mathrm{MHz}, \mathrm{CDCl}_{3}\right) \delta 172.53,155.78$, 
148.86, 146.80, 135.66, 131.07, 128.53, 128.24, 123.37, 116.79, 109.06, 80.74, 66.54, 44.76, 30.22, 28.20. Exact mass calcd. $(\mathrm{M}+\mathrm{H})$ for $\mathrm{C}_{22} \mathrm{H}_{25} \mathrm{BrN}_{4} \mathrm{O}_{4}$ : 489.1137; found: 489.1147 .

(S)-tert-Butyl 2-(4-methoxyphenyl)-1-(6-(trifluoromethyl)-[1,2,4]triazolo[4,3-a]pyridin-3yl)ethylcarbamate (2o). White solid, 48\% yield; ${ }^{1} \mathrm{H} \mathrm{NMR}\left(500 \mathrm{MHz}, \mathrm{CDCl}_{3}\right) \delta 8.09$ (s, $\left.1 \mathrm{H}\right)$, 7.77 (d, 1H, J= $10 \mathrm{~Hz}$ ), 7.25 (d, 1H, J= $10 \mathrm{~Hz}$ ), 7.04 (d, 2H, J= $8.8 \mathrm{~Hz}$ ), 6.71 (d, 2H, J= 8.8 Hz), 5.65-5.55 (m, 1H), 5.5.45-5.35 (m, $1 \mathrm{H}), 3.70$ (s, 3H), 3.5-3.4 (m, 2H), 1.37 (s, 9H). ${ }^{13} \mathrm{C}$ NMR $\left(125 \mathrm{MHz}, \mathrm{CDCl}_{3}\right) \delta 158.81,155.45,149.44,148.53,130.32,128.01,122.99,122.46$ (q, J= 272 Hz), 117.94 (q, J= $36 \mathrm{~Hz}$ ), 117.17, 114.06, 80.74, 55.12, 48.00, 39.80, 28.13. Exact mass calcd. $(\mathrm{M}+\mathrm{H})$ for for $\mathrm{C}_{21} \mathrm{H}_{23} \mathrm{~F}_{3} \mathrm{~N}_{4} \mathrm{O}_{3}$ : 437.1812; found: 437.1801. Elemental Analysis for $\mathrm{C}_{21} \mathrm{H}_{23} \mathrm{~F}_{3} \mathrm{~N}_{4} \mathrm{O}_{3}$ : calcd. C, 57.79\%; H, 5.31\%; N, 12.84\%; found: C, 56.80\%; H, 5.19\%; N, $12.56 \%$.

(S)-tert-Butyl 2-(4-methoxyphenyl)-1-(6-bromo-[1,2,4]triazolo[4,3-a]pyridin-3-yl)ethylcarbamate (2p). White solid, 21\% yield; ${ }^{1} \mathrm{H}$ NMR (500 MHz, $\left.\mathrm{CDCl}_{3}\right) \delta 7.84(\mathrm{~s}, 1 \mathrm{H}), 7.57$ (d, 1H, J=9.3 $\mathrm{Hz}$ ), 7.19 (d, 1H, J= $10 \mathrm{~Hz}$ ), 7.05 (d, 2H, J= $8.8 \mathrm{~Hz}$ ), 6.73 (d, 2H, J= 8.2 Hz), 5.56-5.48 (m, 1H), 5.4-5.3 (m, 1H), 3.73 (s, 3H), 3.47-3.38 (m, 2H), 1.38 (s, 9H). ${ }^{13} \mathrm{C}$ NMR (125 MHz, $\left.\mathrm{CDCl}_{3}\right)$ 158.74, 155.80, 149.00, 147.50, 130.74, 130.41, 128.22, 122.81, 116.65, 114.04, 108.68, 80.10, 55.23, 47.88, 39.79, 28.21. Exact mass calcd. (M+H) for $\mathrm{C}_{20} \mathrm{H}_{23} \mathrm{BrN}_{4} \mathrm{O}_{3}$ : 447.1032; found: 447.1018. Elemental Analysis for $\mathrm{C}_{20} \mathrm{H}_{23} \mathrm{BrN}_{4} \mathrm{O}_{3}$ : calcd. C, 53.70\%; H, 5.18\%; N, 12.52\%; found: C, 53.63\%; H, 4.88\%; N, 12.49\%.

(R)-(9H-Fluoren-9-yl)methyl 2-tert-butoxy-1-(6-(trifluoromethyl)-[1,2,4]triazolo[4,3-a]pyridin-3yl)ethylcarbamate (2q). White solid, 27\% yield; ${ }^{1} \mathrm{H} \mathrm{NMR}\left(500 \mathrm{MHz}, \mathrm{CDCl}_{3}\right) \delta 8.79$ (br. s., $\left.1 \mathrm{H}\right)$, 7.83 (d, 1H, J= 9.3 Hz), 7.74 (d, 2H, J= 7.7 Hz), 7.57 (d, 2H, J= $7.1 \mathrm{~Hz}$ ), 7.34-7.42 (m, 3H), 7.26-7.30 (m, 2H), 6.36 (d, 1H, J=7.7 Hz), 5.44-5.50 (m, 1H), 4.43 (d, 2H, J= 7.1 Hz), 4.20 (t, $1 \mathrm{H}, \mathrm{J}=6.9 \mathrm{~Hz}), 4.00-4.07(\mathrm{~m}, 1 \mathrm{H}), 3.64(\mathrm{t}, 1 \mathrm{H}, \mathrm{J}=8.5 \mathrm{~Hz}), 1.05(\mathrm{~s}, 9 \mathrm{H}) .{ }^{13} \mathrm{C} \mathrm{NMR}(125 \mathrm{MHz}$, $\left.\mathrm{CDCl}_{3}\right) \delta$ ppm 155.94, 149.76, 147.94, 143.61, 143.53, 141.22, 127.67, 126.99, 124.99, 124.09 124.41, 123.19, 119.93, 122.92 (q, J= 272 Hz), 117.08, 117.67 (q, 2C, J= 36 Hz), 74.35, 67.31, 64.89, 47.88, 47.03, 27.09. Exact mass calcd. $(\mathrm{M}+\mathrm{H})$ for $\mathrm{C}_{28} \mathrm{H}_{27} \mathrm{~F}_{3} \mathrm{~N}_{4} \mathrm{O}_{3}$ : 525.2114; found: 525.2102.

3-(Benzyloxymethyl)-6-bromo- $N$-pentyl-[1,2,4]triazolo[4,3-a]pyrimidin-7-amine (2r). White solid, 31\% yield; ${ }^{1} \mathrm{H}$ NMR (500 MHz, DMSO-D6) $\delta 8.80$ (d, 1H, J= 2.6 Hz, 1H), 7.69 (br. s, 1H), 7.35-7.23 (m, 5H), 4.83 (s, 2H), 4.52 (s, 2H), 3.47-3.3 (m, 2H), 1.62-1.52 (m, 2H), 1.35-1.2 (m, 4H), 0.86 (t, 3H, J=6.6 Hz). ${ }^{13} \mathrm{C}$ NMR (125 MHz, DMSO-D6) $\delta$ 153.30, 141.29, 137.58, 131.85, 128.22, 127.87, 127.63, 98.68, 71.41, 61.17, 41.43, 28.58, 27.67, 21.88, 13.88. Exact mass calcd. $(\mathrm{M}+\mathrm{H})$ for $\mathrm{C}_{18} \mathrm{H}_{22} \mathrm{BrN}_{5} \mathrm{O}$ : 404.1086; found: 404.1096. Elemental Analysis for $\mathrm{C}_{18} \mathrm{H}_{22} \mathrm{BrN}_{5} \mathrm{O}$ : calcd. C, 53.47\%; H, 5.48\%; N, 17.32\%; found: C, 53.40\%; H, 5.21\%; N, $17.10 \%$.

Methyl 6-bromo-7-(pentylamino)-[1,2,4]triazolo[4,3-a]pyrimidine-3-carboxylate (2s). White solid, 53\% yield; ${ }^{1} \mathrm{H}$ NMR (500 MHz, DMSO-D6) $\delta 9.02$ (s, 1H), 8.43 (br. s, 1H), 3.96 (s, 3H), 3.5-3.4 (m, 2H), 1.60 (quintuplet, $2 \mathrm{H}, \mathrm{J}=7.4 \mathrm{~Hz}$ ), 1.35-1.22 (m, 4H), $0.87(\mathrm{t}, 3 \mathrm{H}, \mathrm{J}=6.7 \mathrm{~Hz}) .{ }^{13} \mathrm{C}$ NMR (125 MHz, DMSO-D6) $\delta$ 156.96, 154.79, 152.60, 134.86, 133.20, 101.18, 52.92, 41.43, 
28.52, 27.51, 21.83, 13.87. Exact mass calcd. $(\mathrm{M}+\mathrm{H})$ for $\mathrm{C}_{12} \mathrm{H}_{16} \mathrm{BrN}_{5} \mathrm{O}_{2}$ : 342.0566; found: 342.0572 .

Ethyl 2-(6-bromo-7-(pentylamino)-[1,2,4]triazolo[4,3-a]pyrimidin-3-yl)acetate (2t). White solid, 60\% yield; ${ }^{1} \mathrm{H}$ NMR (500 MHz, DMSO-D6) $\delta 9.36(\mathrm{~s}, 1 \mathrm{H}), 8.98-8.9(\mathrm{~m}, 1 \mathrm{H}), 4.31(\mathrm{~s}, 2 \mathrm{H})$, 4.13 (q, 2H, J=6.7 Hz), 3.52-3.44 (m, 2H), 1.61 (quintuplet, 2H, J= 7.4 Hz), 1.29 (m, 4H), 1.20 (t, 4H, J=6.7 Hz), 0.87 (t, 3H, J=6.7 Hz). ${ }^{13} \mathrm{C}$ NMR (125 MHz, DMSO-D6) $\delta$ 166.91, 156.30, 148.62, 139.70, 133.19, 101.01, 61.51, 41.85, 30.63, 28.45, 27.35, 21.8, 13.89. Exact mass calcd. $(\mathrm{M}+\mathrm{H})$ for $\mathrm{C}_{14} \mathrm{H}_{20} \mathrm{BrN}_{5} \mathrm{O}_{2}$ : 370.0879; found: 370.0873 .

Methyl 7-(benzylamino)-6-bromo-[1,2,4]triazolo[4,3-a]pyrimidine-3-carboxylate (2u). White solid, 22\% yield; ${ }^{1} \mathrm{H}$ NMR (500 MHz, DMSO-D6) $\delta 9.08$ (s, 1H), 9.01-8.94 (m, 1H), 7.40-7.20 (m, 5H), 4.69 (d, 2H, J=6.0 Hz), $3.96(\mathrm{~s}, 3 \mathrm{H}) .{ }^{13} \mathrm{C}$ NMR (125 MHz, DMSO-D6) $\delta$ 156.94, 154.98, 152.42, 137.95, 134.97, 133.55, 128.34, 127.29, 127.04, 101.07, 52.95, 44.54. Exact mass calcd. $(\mathrm{M}+\mathrm{H})$ for $\mathrm{C}_{14} \mathrm{H}_{12} \mathrm{BrN}_{5} \mathrm{O}_{2}$ : 362.0253; found: 362.0248 .

\section{References and Notes}

1. (a) Lawson, E. C.; Hoekstra, W. J.; Addo, M. F.; Andrade-Gordon, P.; Damiano, B. P.; Kauffman, J. A.; Mitchell, J. A.; Maryanoff, B. E. Bioorg. Med. Chem. Lett. 2001, 11, 2619. (b) Baraldi, P. G.; Fruttarolo, F.; Tabrizi, M. A.; Preti, D.; Romagnoli, R.; El-Kashef, H.; Moorman, A.; Varani, K.; Gessi, S.; Merighi, S.; Borea, P. A. J. Med. Chem. 2003, 46, 1229. (c) Livi, O.; Scartoni, V. Farmaco 1997, 52, 205. (d) Roberts, D. A.; Bradbury, R. H.; Brown, D.; Faull, A.; Griffiths, D.; Major, J. S.; Oldham, A. A.; Pearce, R. J.; Ratcliffe, A. H.; Revill, J.; Waterson, D. J. Med. Chem. 1990, 33, 2326. (e) McClure, K. F.; Letavic, M. A.; Kalgutkar, A. S.; Gabel, C. A.; Audoly, L.; Barberia, J. T.; Braganza, J. F.; Carter, D.; Carty, T. J.; Cortina, S. R., Bioorg. Med. Chem. Lett. 2006, 16, 4339.

2. (a) Jones, G.; Sliskovic, D. R. Adv. Heterocyclic Chem. 1983, 34, 79. (b) Zhang, Z.-Y.; Sun, X.-W. Heterocycles 1998, 48, 561. (c) Lawson, E. C.; Maryanoff, B. E.; Hoekstra, W. J. Tetrahedron Lett. 2000, 41, 4533. (d) Schneller, S. W.; Bartholomew, D. G. J. Heterocycl. Chem. 1978, 15, 439. (e) Shaban, M. A. E.; Morgan, A. E. A. Adv. Heterocyclic Chem. 2000, 77, 345. (f) Potts, K. T.; Burton, H. R. J Org Chem. 1966, 31, 251. (g) Potts, K. T., Burton, H. R.; Roy, S. K. J. Org. Chem. 1966, 31, 265. (h) Potts, K.T.; Burton, H.R.; Crawford; T.H.; Thomas, S.W. J. Org. Chem. 1966, 31, 3522.

3. (a) Wamhoff, H.; Zahran, M. Synthesis, 1987, 876. (b) Collins, I.; Castro, J. L.; Street, L. J. Tetrahedron Lett. 2000, 41, 781. (c) Kim, D.; Wang, L.; Hale, J. J.; Lynch, C. L.; Budhu, R. J.; MacCoss, M.; Mills, S. G.; Malkowitz, L.; Gould, S. L.; DeMartino, J. A. Bioorg. Med. Chem. Lett. 2005, 15, 2129. (d) Moulin, A.; Martinez, J.; Fehrentz, J.-A. Tetrahedron Lett. 2006, 47, 7591. 
4. (a) Mitsunobu, O.; Yamada, M. Bull. Chem. Soc. Jpn. 1967, 40, 2380. (b) Mitsunobu, O.; Yamada; M.; Mukaiyama, T. Bull. Chem. Soc. Jpn. 1967, 40, 935. (c) Valentine, D. H., Jr.; Hillhouse, J. H. Synthesis 2003, 317. (d) Hughes, D. L. Org. Prep. Proc. Int. 1996, 28, 127.

5. (a) De Lombaert, S.; Blanchard, L.; Tan, J.; Sakane, Y.; Berry, C.; Ghai, R. D. Bioorg. Med. Chem. Lett. 1995, 5, 145. (b) Duncia, J. V.; Pierce, M. E.; Santella, J. B. III. J. Org. Chem. 1991, 56, 2395.

6. (a) Dallinger, D.; Kappe, C. O. Synlett 2002, 11, 1901. (b) Jenkins, I. D.; Mitsunobu, O. in Handbook of Reagents for Organic Synthesis; Pearson, A. J.; Roush, W. R. J. Eds; Wiley and Son: New York, 1999; p 459.

7. $\quad$ Wang, F.; Hauske, J. R. Tetrahedron Lett. 1997, 38, 6529.

8. Other phosphine based amide dehydration reagents have been reported: (a) Sugimoto, O.; Mori, M.; Moriya, K.; Tanji, K.-i. Helv. Chim. Acta 2001, 84, 1112. (b) Zhong, Y.-L.; Lee, J.; Reamer, R. A.; Askin, D. Org. Lett. 2004, 6, 929.

9. Konnecke, A.; Dorre, R.; Lippmann, E. Tetrahedron Lett. 1978, 19, 2071.

10. Similar conditions have been used for azidation of 1,2- and 1,3-diols. See: He, L.; Wanunu, M.; Byun, H.-S.; Bittman, R. J. Org. Chem. 1999, 64, 6049.

11. It has been proposed that when using $\mathrm{HN}_{3}$ in the Mitsunobu reaction, the azide may add to the phosphonium ylide intermediate and increase its reactivity. See: Afonso, C. M.; Barros, M. T.; Godinho, L. S.; Maycock, C. D. Tetrahedron 1994, 50, 9671.

12. (a) Varasi, M.; Walker, K. A. M.; Maddox, M. L. J. Org. Chem. 1987, 52, 4235. (b) Schenk, S.; Weston, J.; Anders, E. J. Am. Chem. Soc. 2005, 127, 12566.

13. Zinc (II) azide bipyridine complex in combination with $\mathrm{Ph}_{3} \mathrm{P} / \mathrm{DIAD}$ has been used for azidation of alcohol see Viaud, M. C.; Rollin, P. Synthesis 1990, 130.

14. A referee pointed out the following reference: Volante, R. P. Tetrahedron Lett. 1981, 22, 3119 where the formation of a precipitate was observed within 30 min upon adding DIAD to $\mathrm{Ph}_{3} \mathrm{P}$ at a concentration of $0.4 \mathrm{M}$ in THF at $0{ }^{\circ} \mathrm{C}$. They reported that this precipitate was "essential for the success of this reaction." In our case, we observed the formation of the precipitate only in the presence of TMS-N $\mathrm{N}_{3}$ at room temperature and a concentration of 0.1 $\mathrm{M}$ and as low as $0.05 \mathrm{M}$. When the substrate is present, the precipitate is often not observed or is seen only transiently. It is possible that we observed the formation of the same species as Volante and that the role of the TMS- $\mathrm{N}_{3}$ is to speed the formation of this intermediate but the fact that we do see an azide band in the IR of the solid suggest that we have a different species.

15. General reaction conditions to form triazolopyridine 2a-2q: DEAD (1.2 mmol, neat or 40\% in toluene) was added to a solution of hydrazide (1.0 mmol), triphenylphosphine (1.2 mmol), and $\mathrm{TMS}_{3} \mathrm{~N}_{3}(1.1 \mathrm{mmol})$ in $\operatorname{THF}(0.1-1.0 \mathrm{M})$ at room temperature. Diisopropyl azodicarboxylate (DIAD) works equally well. The reaction was found to be exothermic when performed on a larger scale $(>10 \mathrm{mmol})$. The resulting brown solution was stirred at room temperature until the reaction was complete (from minutes to $12 \mathrm{~h}$ ). The products 
were purified by silica gel chromatography using an appropriate solvent mixture (using gradients from $\mathrm{CH}_{2} \mathrm{Cl}_{2}$ to $5 \% \mathrm{CH}_{3} \mathrm{OH}$ in $\mathrm{CH}_{2} \mathrm{Cl}_{2}$ or from hexanes to ethyl acetate).

16. General reaction conditions to form triazolopyrimidines (2r-2u) example 2r: DEAD (370 $\mu \mathrm{L}, 2.3 \mathrm{mmol}$ ) was rapidly added to a solution of triphenylphosphine (493 $\mathrm{mg}, 1.88 \mathrm{mmol}$ ), $\mathrm{TMS}^{-\mathrm{N}_{3}} \quad(1.60 \mathrm{mmol})$ and 2-(benzyloxy)-N'-(5-bromo-4-(pentylamino)-pyrimidin-2yl)acetohydrazide (661 mg, $1.57 \mathrm{mmol}$ ) in THF ( $8 \mathrm{~mL}, \sim 0.2 \mathrm{M})$. Gas evolution was observed and a white precipitate formed. The mixture was stirred $30 \mathrm{~min}$ at room temperature and at $50^{\circ} \mathrm{C}$ for $2 \mathrm{~h}$ during which time the precipitate disappeared. $\mathrm{HCl}$ ( $4 \mathrm{~N}$ in dioxane, $5 \mathrm{~mL}$ ) was added and the solvents were removed under a stream of nitrogen. The paste was suspended in $\mathrm{CH}_{2} \mathrm{Cl}_{2}(6 \mathrm{~mL})$ and the white solid was filtered and dried under vacuum to give $317 \mathrm{mg}$ of white solid (50\% yield).

17. Valeur, E.; Bradley, M. Chem. Comm. 2005, 1164.

18. McClure, K. F.; Abramov, Y. A.; Laird, E. R.; Barberia, J. T.; Cai, W.; Carty, T. J.; Cortina, S. R.; Danley, D. E.; Dipesa, A. J.; Donahue, K. M.; Dombroski, M. A.; Elliott, N. C.; Gabel, C. A.; Han, S.; Hynes, T. R.; LeMotte, P. K.; Mansour, M. N.; Marr, E. S.; Letavic, M. A.; Pandit, J.; Ripin, D. B.; Sweeney, F. J.; Tan, D.; Tao, Y., J. Med. Chem. 2005, 48, 5728. 